\title{
Tribological properties of low-temperature graphite fluorides. Influence of the structure on the lubricating performances
}

\author{
P. Thomas ${ }^{\text {a }}$, K. Delbé ${ }^{\text {, }}$, D. Himmel ${ }^{\text {a }}$, J.L. Mansot ${ }^{\text {a, } *, ~ F . ~ C a d o r e ́ ~}{ }^{\text {a }}$, K. Guérin ${ }^{\text {, }}$, \\ M. Dubois ${ }^{\mathrm{b}}$, C. Delabarre ${ }^{\mathrm{b}}$, A. Hamwi ${ }^{\mathrm{b}}$ \\ ${ }^{a}$ Groupe de Technologie des Surfaces et Interfaces (GTSI), EA 2432, Faculté des Sciences Exactes et Naturelles, \\ Université des Antilles et de la Guyane, 97159 Pointeà Pitre Cedex, France \\ ${ }^{\mathrm{b}}$ Laboratoire des Matériaux Inorganiques, Université Blaise Pascal de Clermont-Ferrand, UMR CNRS-6002, 63177 Aubière Cedex, France
}

\begin{abstract}
The present work is concerned with the study of the tribological properties of various fluorinated carbon phases obtained at room temperature and then post-treated under fluorine atmosphere at different temperatures. The tribological tests evidence good intrinsic properties for all the compounds (friction coefficient in the range 0.07-0.09). Differences appear after few cycles. Friction measurements after 100 cycles and complementary Raman analyses of the tribofilm remaining in the wear scar point out that long term tribologic properties of the fluorinated compounds strongly depend on the evolution undergone by the materials under friction. The release of HF molecules, the loss of fluorine and partial rebuilding of graphitic phases are at the origin of the degradation of the friction properties. The good properties of the compounds posttreated at temperature in the range $150-300{ }^{\circ} \mathrm{C}$ are attributed to the chemical and structural stability of these compounds under friction.
\end{abstract}

Keyword: C. Raman spectroscopy

\section{Introduction}

In the wide range of materials commonly used as solid lubricants, good lubricating performances are obtained in the case of lamellar compounds presenting basic properties such as thermal stability, low shear strength and convenient adherence to substrate surface. Thus, graphite fluorides are known to present interesting tribological behaviour [1].

Commercial graphite fluorides are generally prepared by direct reaction of fluorine gas over graphite at temperature ranging from 300 to $600{ }^{\circ} \mathrm{C}$. The resulting $\left(\mathrm{CF}_{x}\right)_{n}$ compounds, called $\mathrm{CF}(\mathrm{HT})$, are characterized by a strong covalent $\mathrm{C}-\mathrm{F}$ bond associated to $\mathrm{a} \mathrm{sp}^{3}$ hybridization of carbon atoms [2]. The tribological properties of $\mathrm{CF}(\mathrm{HT})$ compounds strongly depend on various parameters and especially fluorine content and environmental atmosphere $[3,4]$. The corresponding friction coefficients range from $\mu=0.05$ to 0.15 .

Many studies have been performed to obtain graphite fluorides at lower synthesis temperature with high fluorine

\footnotetext{
* Corresponding author. Tel.: +33 59093 8668; fax: +33 590938675 .

E-mail address: jean-louis.mansot@univ-ag.fr (J.L. Mansot).
}

contents in which fluorine atoms are weakly linked to carbon layers (essentially for electrochemical applications as cathode materials in lithium batteries) [5,6]. Thus, highly fluorinated first stage compounds ( $\mathrm{F} / \mathrm{C}$ ratio $>0.8)$, called $\mathrm{CF}(\mathrm{LT})$, were obtained at room temperature in the presence of a gaseous mixture of a volatile fluoride such as $\mathrm{IF}_{5}, \mathrm{HF}$ and $\mathrm{F}_{2}$ [7]. Hamwi et al. then studied the effects of a fluorination post-treatment on the physicochemical characteristics of $\mathrm{CF}(\mathrm{LT})$ compounds and in particular the evolution of the nature of the $\mathrm{C}-\mathrm{F}$ bond in relation with the re-fluorination temperature [8].

The aim of this work is to investigate the friction behaviour of $\mathrm{CF}(\mathrm{LT})$ materials and to correlate the tribological performances of these compounds to their structure resulting from the fluorination post-treatment. Special attention is paid to the structural and chemical changes undergone by the fluorinated materials during the friction process and the resulting evolutions of the tribological properties.

\section{Experimental}

\subsection{Materials}

The starting fluorinated material is obtained at room temperature, by the reaction of natural graphite 
from Madagascar with a gaseous mixture of $\mathrm{HF}, \mathrm{F}_{2}$ and $\mathrm{IF}_{5}$. The chemical composition of the obtained product is $\mathrm{CF}_{0.73}\left(\mathrm{IF}_{5}\right)_{0.02}(\mathrm{HF})_{0.06}$. A thermal post-treatment is then performed under fluorine gas at temperatures ranging from 100 to $600{ }^{\circ} \mathrm{C}$ [9]. The compounds will be named CF(LT)- $T_{\text {FPT }}$ where $T_{\mathrm{FPT}}$ is the post-treatment temperature.

\subsection{Tribologic tests}

The tribologic properties of the compounds are evaluated using a ball-on-plane tribometer consisting of an AISI 52100 steel ball rubbing against an AISI 52100 steel plane. After polishing and ultrasonically cleaning in ethanol, the tested film is deposited on the plane by the burnishing technique. The tribological conditions are the following:

Metallurgy: ball AISI 52100 Vickers hardness 850; plane AISI 52100 Vickers hardness 850

Ball diameter: $9.5 \mathrm{~mm}$; ball roughness: $10 \mathrm{~mm}$ peak to peak Plane dimensions: $10 \times 2 \mathrm{~mm}$; plane roughness: $100 \mathrm{~mm}$ peak to peak

Normal load: $10 \mathrm{~N}$ leading to a theoretical Hertzian diameter of $140 \mu \mathrm{m}$ and a mean contact pressure of $0.65 \mathrm{GPa}$.

Temperature: $25^{\circ} \mathrm{C}$

Sliding speed: $6 \mathrm{~mm} \mathrm{~s}^{-1}$

The relatively important roughness of the plane is needed for good adherence of compounds on the surface. The friction coefficient is measured with a computer-based data acquisition system. Two types of measurements are carried out:

- The evaluation of the intrinsic friction properties of the fluorinated compounds in the three first cycles

- The evolution of friction coefficient after 100 cycles (where physical and chemical friction transformations can take place).

\subsection{Raman spectrometry investigations}

Raman spectroscopy studies were performed on a HR 800 Horiba multi channel spectrometer using a Peltier cooled CCD detector for signal recording. Either laser red $(632 \mathrm{~nm})$ or green $(532 \mathrm{~nm})$ exciting lines can be used. For this work the green line was chosen. The pre-monochromator is a notch filter and the monochromator a 150 line $/ \mathrm{mm}$ holographic grating. In standard conditions (objective lens $\times 50$, confocal hole $500 \mu \mathrm{m}$, spectrometer entry aperture $500 \mu \mathrm{m}$ ) the probe diameter is of $5 \mu \mathrm{m}$, the wavenumber resolution is of $5 \mathrm{~cm}^{-1}$ and dispersion $2.5 \mathrm{~cm}^{-1} /$ pixel.

\section{Results and discussion}

The structural/chemical evolutions of the fluorinated compounds as a function of fluorination post-treatment temperature $\left(T_{\mathrm{FPT}}\right)$, extensively studied in previous work [8-14] are schematically drawn in Fig. 1 and the evolutions
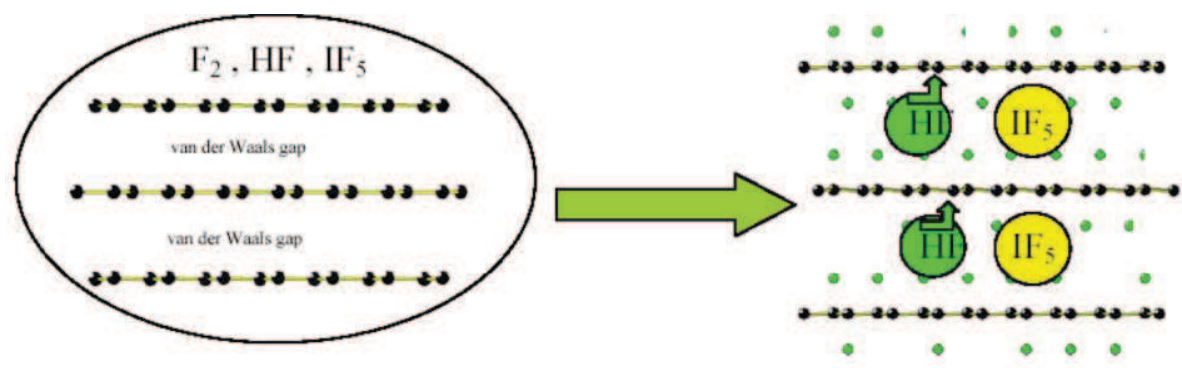

$100^{\circ} \mathrm{C}<\mathrm{T}_{\text {FPT }}<400^{\circ} \mathrm{C}$
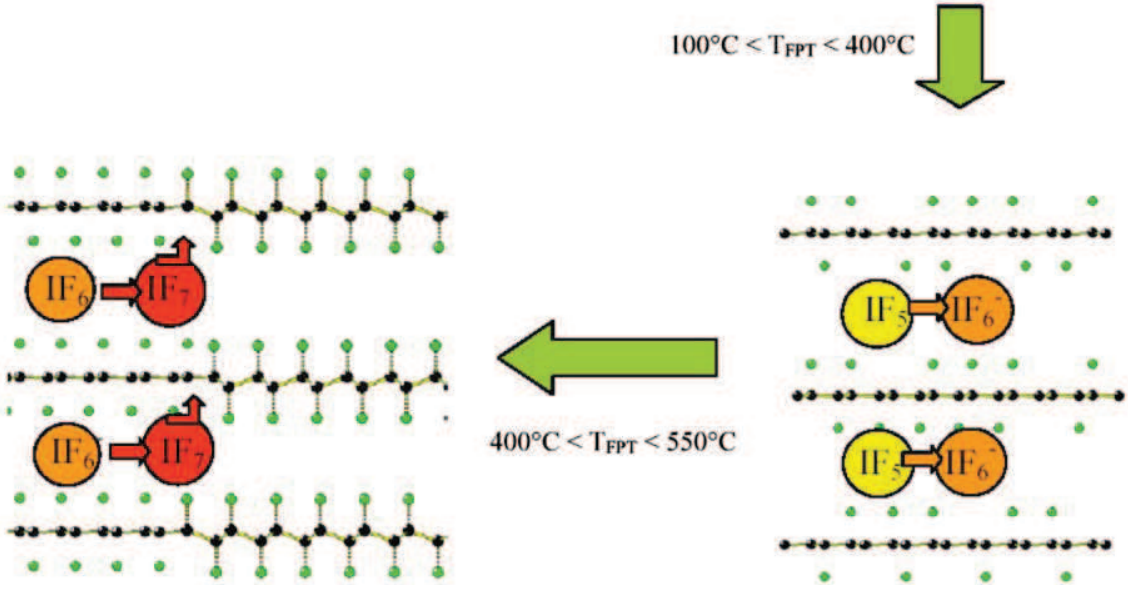

Fig. 1. Schematic evolution of the structure of $\mathrm{CF}(\mathrm{LT})$ materials as a function of post-treatment temperature $\left(T_{\mathrm{FPT}}\right)$. 


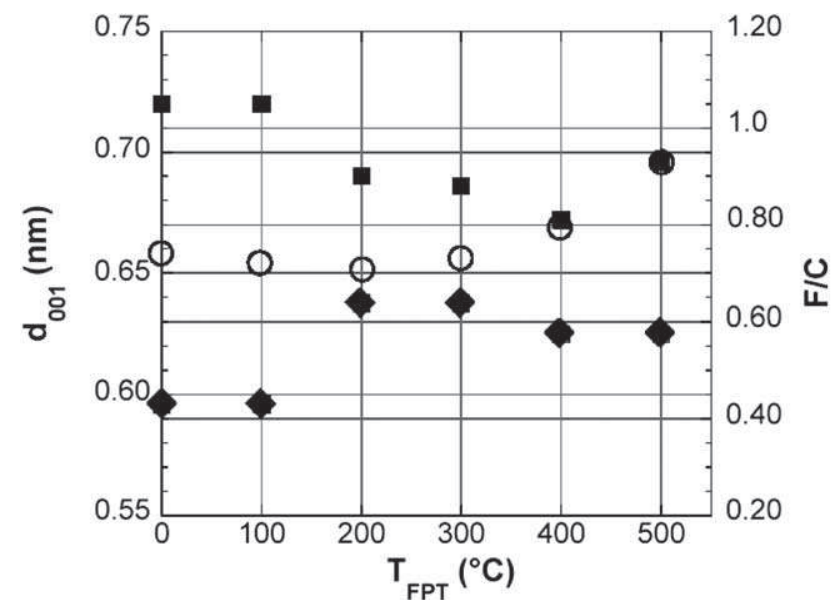

Fig. 2. Evolution of the interlayer spacing $d_{001}(\mathrm{~nm})(\diamond)$ and of the total Fluorine on Carbon (TF/C) ratio ( $\square$ ) and the carbon bonded fluorine on carbon $(\mathrm{F}-\mathrm{C} / \mathrm{C})$ ratio $(\mathrm{O})$ as a function of post-treatment Temperature $\left(T_{\mathrm{FPT}}\right)$.

of interlayer spacing and fluorine contents are presented in Fig. 2.

The physical and chemical characterization of the compounds indicate that:

- At room temperature, in the presence of fluorine and catalysts $\left(\mathrm{HF}\right.$ and $\left.\mathrm{IF}_{5}\right)$, the resulting materials contain $\mathrm{HF}$ and $\mathrm{IF}_{5}$ as intercalated compounds, the fluorine carbon bonds are 'semi-ionic' and the planar shape of the carbon layers is conserved.

- For post-treatment temperatures in the range $100-300{ }^{\circ} \mathrm{C}$, $\mathrm{HF}$ molecules are removed (total elimination above $150{ }^{\circ} \mathrm{C}$ ), the fluorine content decreases, $\mathrm{IF}_{5}$ species evolved into $\mathrm{IF}_{6}^{-}$, the $\mathrm{C}-\mathrm{F}$ bonds remains semi-ionic and the planar shape of carbon layers is maintained.

- For post-treatment temperatures upper than $400{ }^{\circ} \mathrm{C}, \mathrm{IF}_{6}^{-}$ evolved into $\mathrm{IF}_{7}$ which is progressively eliminated. The fluorine content increases, an increasing yield of $\mathrm{C}-\mathrm{F}$ bonds becomes covalent leading to domains where the carbon cycles adopt a armchair conformation.

- For $T_{\mathrm{FPT}}>500{ }^{\circ} \mathrm{C}, \quad \mathrm{IF}_{n}$ species are almost totally removed, the $F / C$ ratio is close to $1, \mathrm{C}-\mathrm{F}$ bonds are covalent, the armchair conformation is extended to the whole material.

All these evolution concerning the nature of the intercalated species and the changes of the $\mathrm{C}-\mathrm{F}$ bonding should modify the interlayer interactions and consequently influence the tribological performances of the fluorinated compounds obtained at various post-treatment temperatures.

The friction coefficient obtained for the various $\mathrm{CF}(\mathrm{LT})$ $T_{\text {FPT }}$ materials at the beginning of the test (intrinsic tribologic properties) and after 100 cycles (properties of the tribo-modified phases) are presented in the Fig. 3.

As it can be seen, all phases present good intrinsic tribologic properties (friction coefficient ranging between 0.07 and 0.09). It must be noticed that the CF(LT)-300 compound presents the lowest friction coefficient $(\mu=0.07)$.

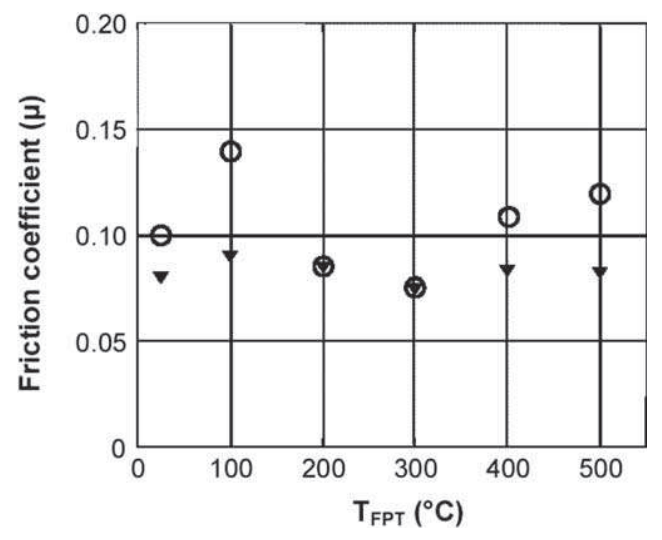

Fig. 3. Friction coefficient of $\mathrm{CF}(\mathrm{LT})-T_{\mathrm{FPT}}$ materials during the three first cycles $(\boldsymbol{\nabla})$ and at 100 cycles $(\bigcirc)$.

After 100 cycles, the friction coefficient of the CF(LT)-0 and $\mathrm{CF}(\mathrm{LT})-100$ materials severely increase. The wear scars show heavy corrosion and wear. These degradations of the tribologic properties as a function of test duration are attributed to the release of $\mathrm{HF}$ molecules, entrapped in the lamellar structure, during the friction process. These HF molecules severely react with the contacting iron substrates leading to the increase of the friction coefficient and the wear rate.

In the case of the CF(LT)-200 and CF(LT)-300 materials, the friction coefficients remain remarkably stable $(0.08$ and 0.07, respectively) during all the test. In a first step, these tribologic properties can be attributed to the absence of HF molecules in the structure and to the enhancement of the interlayer spacing probably due to the presence of $\mathrm{IF}_{6}^{-}$ intercalated species.

Suprisingly, the compounds obtained for $T_{\mathrm{FPT}}>400{ }^{\circ} \mathrm{C}$ show a continuous increase of their friction coefficients to raise a stable value of 0.12 after 100 cycles. These evolutions point out the evolution of these $\mathrm{CF}(\mathrm{LT}))-T_{\mathrm{FPT}}$ under friction.

In order to understand this behaviour, Raman spectra were recorded on the initial $\mathrm{CF}(\mathrm{LT}))-T_{\mathrm{FPT}}$ compounds and on the phases remaining in the wear scars after 100 cycles. The spectra are presented in Fig. 4. All the spectra of the initial compounds present the two characteristic graphene bands corresponding to $G\left(1588 \mathrm{~cm}^{-1}\right)$ and $D\left(1344 \mathrm{~cm}^{-1}\right)$ modes. The $\mathrm{D}$ mode is observed in the case of polycrystalline carbon and is attributed to the disorder induced $\mathrm{A}_{1 \mathrm{~g}}$ mode [11].

The $D / G$ ratio (Fig. 5) decreases very slightly as a function of the post-treatment temperature showing a very slight increase of long range order in the graphitic phases.

The spectra do not evidence any significant changes of the peaks frequencies and intensities until $T_{\mathrm{FPT}}=400{ }^{\circ} \mathrm{C}$. Such results are in good agreement with the fact that in this range of temperatures the $\mathrm{C}-\mathrm{F}$ bonding remains mainly semi-ionic [14] and the graphene planes are conserved. The weak intensities of the peaks in the CF(LT)-400 and CF(LT)-500 spectra confirm the low content of aromatic groups in the compounds due to the increasing yield of $\mathrm{C}-\mathrm{F}$ covalent bonds above $400{ }^{\circ} \mathrm{C}$ and the configuration changes induced $\left(\mathrm{C} \mathrm{sp}^{3}\right.$ and chair configuration of saturated cycles). 

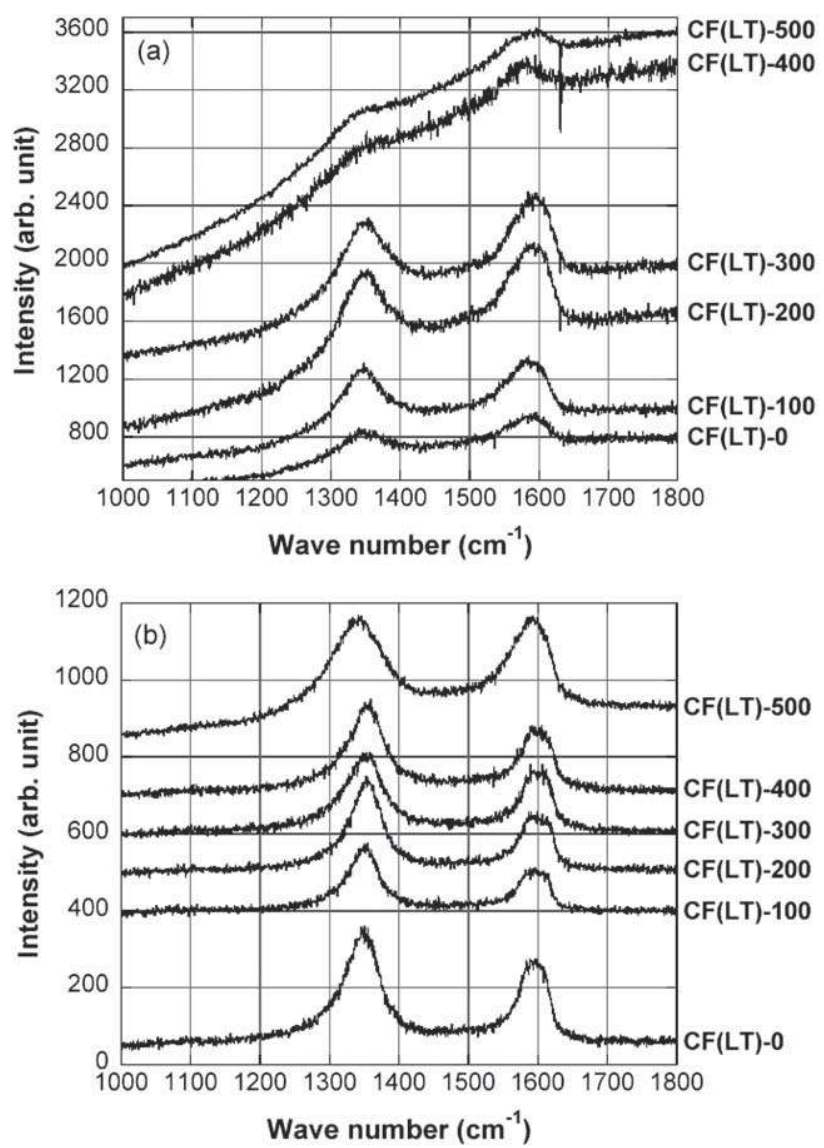

Fig. 4. (a) Raman spectra of $\mathrm{CF}(\mathrm{LT})-T_{\mathrm{FPT}}$ compounds before friction tests. (b) At the end of the friction tests (100 cycles).

A slight lowering of the $G$ mode frequency down to $1573 \mathrm{~cm}^{-1}$ is evidenced for $\mathrm{CF}(\mathrm{LT})-400$ and $\mathrm{CF}(\mathrm{LT})-500$ materials. Such a behaviour already observed in previous work $[12-13]$ is attributed to the increase of single $\mathrm{C}-\mathrm{C}$ bonds due to the increase of $\mathrm{C}-\mathrm{F}$ covalent bonding.

After friction, all spectra acquired in the wear scars (on the so called tribofilm) exhibit the $G$ and $D$ peaks with similar

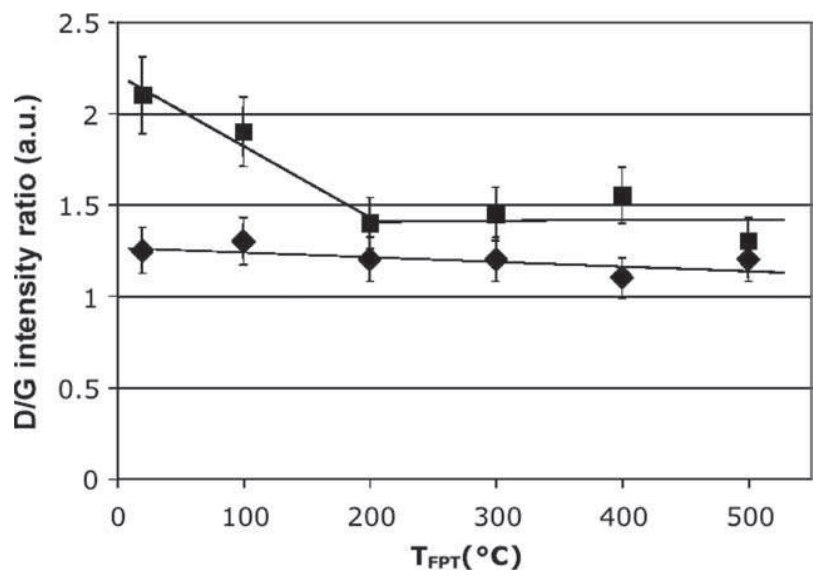

Fig. 5. Evolution of the $D / G$ areas ratio before friction tests ( of the friction tests (100 cycles) $(\diamond)$ intensities. This result points out similar amount of graphitic phases in the various tribofilms.

The $D / G$ intensity ratio (Fig. 5) drastically decreases from 2.2 for the room temperature $\mathrm{CF}(\mathrm{LT})$ down to 1.3 for $\mathrm{CF}(\mathrm{LT})$ post-treated above $200{ }^{\circ} \mathrm{C}$. It evidences that for low temperature $\mathrm{CF}(\mathrm{LT})$ the tribofilm is highly disordered whereas for posttreatment temperature above $200{ }^{\circ} \mathrm{C}$ the friction process does not induce significant structural evolution.

The comparison of the spectra reported in the Fig. $4 a$ and $b$ shows that the $\mathrm{G}$ mode slightly moves to higher frequencies for $\mathrm{CF}(\mathrm{LT})$ post treated up to $300{ }^{\circ} \mathrm{C}$. It shows a slight decrease of the single $\mathrm{C}-\mathrm{C}$ bond amount, i.e. a decrease of the fluorine content in the tribofilms.

The spectra recorded onto original $\mathrm{CF}(\mathrm{LT})-400$ and CF(LT)-500 and onto corresponding tribofilms exhibit significant changes. Especially the drastic increase of the $D$ and $G$ bands intensity recorded at the end of the friction experiments points out tribologic induced transformations leading to the partial rebuilding of graphene planes.

The tribologic tests and Raman analyses allow us to conclude that long term tribologic properties of the CF(LT) strongly depend on their evolution during friction, i.e. during the formation of the tribofilm.

The bad properties of the $\mathrm{CF}(\mathrm{LT})$ post treated down to $200{ }^{\circ} \mathrm{C}$ are attributed to the release of $\mathrm{HF}$ molecules under friction.

For $\mathrm{CF}(\mathrm{LT})$ post-treated above $400{ }^{\circ} \mathrm{C}$ the tribofilm contains higher amounts of graphitic phases than in the original compounds implying high losses of fluorine and partial rebuilding of graphene planes. The friction properties of these tribofilms are close to graphite ones in air (friction coefficient 0.12).

The behaviour of the intermediary compounds obtained at 200 and $300{ }^{\circ} \mathrm{C}$ is more interesting. Friction coefficients remain stable during the whole tribologic test and Raman spectra exhibit very slight changes for the compounds, friction processes probably induce breakings of $\mathrm{C}-\mathrm{F}$ bonds. However, the semi-ionic nature of $\mathrm{C}-\mathrm{F}$ bonds, the presence of $\mathrm{IF}_{n}$ intercalated species damping the fluorine diffusion and the presence of many free sites (these compounds present a carbon bonded fluorine on carbon ratio around 0.7) probably allow to the fluorine atoms or molecules released in the structure to create new bonds on other free sites of the structure before their extrusion. The stability of the composition of these materials under friction results in their stable tribologic properties.

\section{Conclusion}

Low temperature graphite fluorides present good lubrication properties as friction coefficients similar to those of conventional $\mathrm{CF}(\mathrm{HT})$ are obtained. Our studies show that several parameters such as the nature of the $\mathrm{C}-\mathrm{F}$ bonds, the presence of intercalated species and the fluorine content strongly influence the tribological properties of the fluorinated phases. The best results are obtained for CF(LT)-200 and $\mathrm{CF}(\mathrm{LT})-300$ characterized by the absence of intercalated 
HF molecules, the planar shape of the carbon layers and the semi ionic nature of the $\mathrm{C}-\mathrm{F}$ bonds stabilized by the intercalated $\mathrm{IF}_{n}$ species. Raman analyses point out that the materials post treated above $400{ }^{\circ} \mathrm{C}$ which structure mainly consist in perfluorinated corrugated layers (armchair configuration of the carbon cycles) loose fluorine during friction tests and that graphite or graphite-like structure is partially restored. The obtained tribofilms present friction properties similar to graphite.

\section{References}

[1] Y. Tsuya, in: T. Nakajima (Ed.), Fluorine-Carbon and Fluoride-Carbon Materials, Tribology of Graphite Fluorides, Marcel Dekker, New York, 1995, pp. 355-380.

[2] Y. Kita, N. Watanabe, Y. Fuji, Chemical composition and crystal structure of graphite fluoride, J. Am. Chem. Soc. 101 (1979) 3832-3841.

[3] R.L. Fusaro, J.E. Sliney, Graphite fluoride $\left(\mathrm{CF}_{x}\right)_{n}$-a new solid lubricant, ASLE Trans. 13 (1970) 56-65

[4] R.L. Fusaro, Mechanisms of graphite fluoride $\left(\mathrm{CF}_{x}\right)_{n}$ lubrication, Wear 53 (1979) 303-323

[5] I. Palchan, D. Davidov, H. Selig, Preparation and properties of new graphite-fluorine intercalation compounds, J. Chem. Soc. Chem. Commun. 12 (1983) 657-658.
[6] T. Nakajima, M. Kawaguchi, N. Watanabe, Electrochemical behaviour of graphite intercalation compounds of fluorine and metal fluorides, Electrochim. Acta 27 (1982) 1535-1538

[7] A. Hamwi, M. Daoud, J.C. Cousseins, Graphite fluorides prepared at room temperature. 1. Synthesis and characterization, Synth. Met. 26 (1988) 89-98.

[8] M. Dubois, K. Guerin, J.P. Pinheiro, Z. Fawal, F. Masin, A. Hamwi, NMR and EPR studies of room temperature highly fluorinated graphite heattreated under fluorine atmosphere, Carbon 42 (2004) 1931-1940.

[9] A. Hamwi, R. Yazami, Secondary solid electrolyte lithium battery, Patent WO90/07798.

[10] K. Guerin, J.P. Pinheiro, M. Dubois, Z. Fawal, F. Masin, R. Yazami, A. Hamwi, Synthesis and characterization of highly fluorinated graphite containing $\mathrm{sp}^{2}$ and $\mathrm{sp}^{3}$ carbon, Chem. Mater. 16 (2004) 1786-1792.

[11] S.Y. Leung, M.S. Dresselhaus, G. Dresselhaus, Infrared and Raman spectroscopy of graphite intercalation compounds, Physica B + C 105 (1981) 375-380.

[12] V. Gupta, T. Nakajima, B. Zemva, Raman scattering of highly fluorinated graphite, J. Fluorine Chem. 110 (2001) 145-151.

[13] V. Gupta, T. Nakajima, Y. Ohzawa, B. Zemva, A study on the formation of graphite fluorides by raman spectroscopy, J. Fluorine Chem. 120 (2003) 143-150.

[14] J. Giraudet, M. Dubois, K. Guerin, J.P. Pinheiro, A. Hamwi, W.E.E. Stone, P. Pirotte, F. Masin, Solid-state ${ }^{19} \mathrm{~F}$ and ${ }^{13} \mathrm{C}$ NMR of room temperature fluorinated graphite and samples thermally treated under fluorine: low-field and high-resolution studies, J. Solid State Chem. 178 (2005) 1262-1268. 